medRxiv preprint doi: https://doi.org/10.1101/2021.01.13.21249597; this version posted January 21, 2021. The copyright holder for this preprint (which was not certified by peer review) is the author/funder, who has granted medRxiv a license to display the preprint in perpetuity.

All rights reserved. No reuse allowed without permission.

\title{
A Whole-Brain Functional Connectivity Model of Alzheimer's Disease Pathology
}

\author{
Ruchika S. Prakash ${ }^{1 *}$, Michael R. McKenna ${ }^{1 \tau}$, Oyetunde Gbadeyan ${ }^{1 \tau}$, Anita R. Shankar ${ }^{1}$, Rebecca Andridge $^{2}$, \\ Douglas W. Scharre ${ }^{3}$ \\ ${ }^{1}$ Department of Psychology, The Ohio State University, OH, USA \\ 2 Division of Biostatistics, The Ohio State University, OH, USA \\ ${ }^{3}$ Department of Neurology, Division of Cognitive Neurology, The Ohio State University Wexner Medical Center, \\ $\mathrm{OH}, \mathrm{USA}$
}

${ }^{ \pm}$Data used in preparation of this article were obtained from the Alzheimer's Disease Neuroimaging Initiative (ADNI) database (adni.loni.usc.edu). As such, the investigators within the ADNI contributed to the design and implementation of $A D N I$ and/or provided data but did not participate in analysis or writing of this report. $A$ complete listing of ADNI investigators can be found at: http://adni.loni.usc.edu/wpcontent/uploads/how_to_apply/ADNI_Acknowledgement_List.pdf

${ }^{*}$ Correspondence concerning this article should be addressed to Ruchika Shaurya Prakash, Department of Psychology, The Ohio State University, 139 Psychology Building, 1835 Neil Avenue, Columbus, OH 43210.

Email: prakash.30@osu.edu

${ }^{\tau}$ Authors contributed equally to the paper.

\section{Keywords}

Whole-brain functional connectivity, machine learning, Alzheimer's disease, global cognition

\section{Author Contributions}

R.S.P conceptualized the study, received funding for the study, supervised the analyses of data, and wrote the first draft of the manuscript with MM and OG. MM and OG conceptualized the study with RP, conducted the analyses, and co-wrote the first draft of the manuscript. AS conducted the analyses with MM and OG and provided feedback on the manuscript. RA conducted the behavioral analyses and provided feedback on the manuscript. DS helped with the conceptualization of the manuscript and provided feedback on the manuscript. 
medRxiv preprint doi: https://doi.org/10.1101/2021.01.13.21249597; this version posted January 21, 2021. The copyright holder for this preprint

(which was not certified by peer review) is the author/funder, who has granted medRxiv a license to display the preprint in perpetuity.

All rights reserved. No reuse allowed without permission.

\begin{abstract}
Early detection of Alzheimer's disease (AD) is a necessity as prognosis is poor upon symptom onset. Although previous work diagnosing AD from protein-based biomarkers has been encouraging, cerebrospinal (CSF) biomarker measurement of $A D$ proteins requires invasive lumbar puncture, whereas assessment of direct accumulation requires radioactive substance exposure in positron emission tomography (PET) imaging. Functional magnetic resonance imaging (fMRI)-based neuromarkers, offers an alternative, especially those built by capitalizing on variance distributed across the entire human connectome. In this study, we employed connectome-based predictive modeling (CPM) to build a model of functional connections that would predict CSF p-tau/A $\beta_{42}$ (PATH-fc model) in individuals diagnosed with Mild Cognitive Impairment (MCl) and AD dementia. fMRI, CSF-based biomarker data, and longitudinal data from neuropsychological testing from the Alzheimer's Disease Neurolmaging Initiative (ADNI) were utilized to build the PATH-fc model. Our results provide support for successful in-sample fit of the PATH-fc model in predicting AD pathology in $\mathrm{MCl}$ and $\mathrm{AD}$ dementia individuals. The PATH-fc model, distributed across all ten canonical networks, additionally predicted cognitive decline on composite measures of global cognition and executive functioning. Our highly distributed pathology-based model of functional connectivity disruptions had a striking overlap with the spatial affinities of amyloid and tau pathology, and included the default mode network as the hub of such network-based disruptions in AD. Future work validating this model in other external datasets, and to midlife adults and older adults with no known diagnosis, will critically extend this neuromarker development work using fMRI.
\end{abstract}

\title{
Significance Statement
}

Alzheimer's disease (AD) is clinical-pathological syndrome with multi-domain amnestic symptoms considered the hallmark feature of the disease. However, accumulating evidence from autopsy studies evince support for the onset of pathophysiological processes well before the onset of symptoms. Although CSF- and PET-based biomarkers provide indirect and direct estimates of AD pathology, both methodologies are invasive. In here, we implemented a supervised machine learning algorithm - connectome-based predictive modeling - on fMRI data and found support for a whole-brain model of functional connectivity to predict $A D$ pathology and decline in cognitive functioning over a twoyear period. Our study provides support for AD pathology dependent functional connectivity disturbances in large-scale functional networks to influence the trajectory of key cognitive domains in $\mathrm{MCl}$ and $\mathrm{AD}$ patients. 
medRxiv preprint doi: https://doi.org/10.1101/2021.01.13.21249597; this version posted January 21, 2021. The copyright holder for this preprint (which was not certified by peer review) is the author/funder, who has granted medRxiv a license to display the preprint in perpetuity.

All rights reserved. No reuse allowed without permission. 
medRxiv preprint doi: https://doi.org/10.1101/2021.01.13.21249597; this version posted January 21, 2021. The copyright holder for this preprint (which was not certified by peer review) is the author/funder, who has granted medRxiv a license to display the preprint in perpetuity.

All rights reserved. No reuse allowed without permission.

\section{Introduction}

According to recent estimates by the Alzheimer's Association, 5.8 million Americans are currently facing AD, with 13.8 million older adults projected to be diagnosed by 2050 (1). This has resulted in significant investment from the National Institutes of Health $(\mathrm{NIH})$ towards understanding the etiology, progression, and treatment of Alzheimer's disease $(2,3)$. Cognitive deficits are considered hallmark symptoms of $A D$, with notable impairment to episodic memory; however, other sub-domains of cognitive functioning are also degraded including executive dysfunction, processing speed, and attentional control (4-7). There is unequivocal evidence from imaging and autopsy studies that the neurodegenerative process in AD, especially alterations in fluid-based and imagingbased biomarkers, initiates well before, and in some instances, without the presence of known cognitive symptoms (4-7). Additionally, autopsy studies also confirm the absence of AD neuropathology in $10-30 \%$ of individuals diagnosed to have AD-related dementia by experts (8), questioning the specificity of the prototypical amnestic clinical syndrome for $A D$ neuropathology. Thus, a research framework recently proposed by the National Institute on Aging has emphasized a paradigm shift in conceptualizing AD away from clinical symptoms to a biologically driven approach, defined by either postmortem or in vivo examination of fluid or imaging biomarkers (2). Furthermore, with no current treatment to reverse the effects of the disease, the prognosis of $A D$ is poor after the appearance of symptoms, making early detection a critical necessity.

Previous research has offered encouraging results in using both CSF-based and imaging-based biomarkers to categorize between healthy controls and individuals with varying stages of $A D(9-12)$. Two wellstudied biomarkers in $A D$ are CSF levels of $A \beta_{42}$, one of the most reliable diagnostic isoforms of $A \beta$, and CSF levels of hyperphosphorylated tau ( $p$-tau), which is thought to be more specific to AD pathology than other measures such as total-tau (13). Of these CSF-based markers, there is increasing support for a ratiometric measure of $p$-tau/A $\beta_{42}$, combining variance across the two critically implicated proteinopathies of amyloidosis and tauopathy, to have one of the best diagnostic accuracies (14-16). For example, Hansson et al.(14) comparing the accuracy rates for the recently developed and reliable Elecsys-based immunoassays of $A \beta 42, t-$ tau/A $\beta 42$, and $p$-tau/A 342 , provided support for the two ratiometric measures to have stronger concordance with amyloid PET than CSF-A $\beta_{42}$ alone. With new radiotracers available for imaging of tau depositions, there is also recent growth in the use of PET to identify imaging-based diagnostic biomarkers of AD pathology (17). However, the invasive nature of repeated lumbar punctures, and the introduction of radioactive substances during PET, necessitate the use of other noninvasive imaging techniques, such as fMRI to develop neuromarkers that reliably predict symptom onset, disease progression, and demonstrate sensitivity to change as a function of key therapeutic agents. Like biomarker accumulation, changes in functional connectivity occur well before the onset of clinical symptoms $(3,18)$, thus positioning functional connectivity as an effective way to predict future cognitive decline.

fMRI is an imaging modality that indirectly captures neuronal activity by modeling the hemodynamic response. Much of the prior research examining functional connectivity changes within AD focused on understanding activity- and connectivity-based disruptions in the default mode network (19), a set of midline cortical regions with early metabolic and histopathological changes as a result of AD (20, 21). However, increasingly, there has also been interest in examining the intra-network changes in other key canonical networks. Although studies repeatedly demonstrate disruptions in intra-network connectivity of large-scale networks supporting cognitive processes, like the frontoparietal network, salience network, and the dorsal attention network, there are significant differences across studies regarding the networks that show disruptions $(22,23)$. Similarly, there are also discrepancies reported in the literature on the extent and pattern of internetwork disconnections seen as a function of aggregation of amyloid and tau proteins, with some studies suggesting reduced anticorrelations between networks with increasing pathology (24-26), and other studies attributing the inter-network dysfunction to aging rather than AD pathogenesis (23). These discrepancies, across studies, thus highlight the limitations of group-based approaches that neither account for the continuous and heterogeneous nature of AD neurodegeneration, nor differentiate between network level changes occurring due to aging compared to those occurring due to neurodegenerative pathologic processes. Furthermore, with recent incorporation of machine learning in analyses of neuroimaging data, the field has witnessed a significant shift in our reliance on investigating one or two canonical networks of the brain, to conceptualizing complex psychiatric and neurological disorders, including AD, as byproducts of systemic changes in the entire connectome (27-29).

Connectome-based predictive modeling (CPM) is one such whole-brain, data-driven approach that allows for the identification of connectivity patterns within the individual's entire connectome that are predictive of disease states, symptom severity, or cognitive functioning $(30,31)$. In what is now considered a set of formative studies in the development of functional MRI-based models, Rosenberg and colleagues, derived and tested the generalizability of a whole-brain, FC-based model of sustained attention: saCPM $(30,32-34)$. The saCPM using leave-one-out cross-validation procedure predicted over $70 \%$ of variance in sustained attention in a cohort of young adults on whom the model was derived (30). More importantly, the saCPM neuromarker was then generalized to predict attention-based deficiencies in children with attention-deficit/hyperactivity disorder (30); 
medRxiv preprint doi: https://doi.org/10.1101/2021.01.13.21249597; this version posted January 21, 2021. The copyright holder for this preprint (which was not certified by peer review) is the author/funder, who has granted medRxiv a license to display the preprint in perpetuity.

All rights reserved. No reuse allowed without permission.

predict cognitive performance on other metrics of attention, like inhibitory control (32) and executive control (33); and serve as a surrogate biomarker for treatment efficacy with increased connectivity following methylphenidate treatment for ADHD (30). Extending this saCPM to older adults, our lab, in collaboration with Rosenberg and colleagues, recently evinced support for the saCPM neuromarker to predict attentional control in healthy older adults, with the saCPM neuromarker explaining $38.4 \%$ of the variance in Stroop task performance across a sample of young adults and older adults (34).

Following the success of the saCPM, there has been a growing interest in the use of CPM to predict symptom severity in neurodegenerative populations (35) as well as in psychiatric populations $(36,30,37,38)$. Within $A D$, Lin et al.(35) is the only study, to our knowledge, examining the utility of CPM in predicting baseline levels of cognitive functioning in the ADNI sample. They found that the increased connectivity within the frontoparietal network and increased connectivity between the frontoparietal network and default mode network were related to worse baseline cognitive scores on the ADAS11 measure of overall cognitive functioning. However, no study, to our knowledge, has yet utilized this approach to explore links between whole-brain patterns of functional connectivity and underlying biological measures in AD, specifically CSF-based biomarkers. Here, we employed the CPM method to develop a whole-brain marker of functional connectivity representing CSF-based AD pathology. Specifically, we used the ratiometric measure of $p$-tau/A $\beta_{42}$ to develop a connectomebased model of FC in symptomatic older adults and further determined the in-sample fit of this model in predicting decline over a period of two years in global cognition, memory functioning, and executive functioning in the same sample.

\section{Results}

Distribution of AD Pathology and Cognitive Composites: We included 62 participants with $\mathrm{MCl}$ and 21 participants with $A D$ in the final sample. As shown in Table 1, participants across the two groups were predominantly White $(91.65 \%)$, with an average age of 72 years, and education of 16 years. $14.3 \%$ of $\mathrm{MCl}$ individuals and $50.8 \%$ of $A D$ individuals were APOE $\varepsilon 4$ positive. Scores on all three of the cognitive composites declined over time (see Table 2), with the largest declines seen for PACC, followed by ADNI-MEM, and ADNI-EF.

Resting-State Connectivity Patterns Predict AD Pathology: We employed connectome-based predictive modeling (see Figure 1) to develop a whole-brain functional connectivity marker of AD pathology. Employing the leave-one-out-cross-validation technique, connectome-based models were trained to predict pathology score for the test participant during each round of the cross-validation. The respective predicted pathology scores were correlated with observed pathology scores to index model performance. This resulted in two distinct subnetworks: 1) a high pathology network, representing a set of edges correlated positively with levels of CSFbiomarker accumulation, and 2) a low pathology network, representing a set of edges negatively associated with pathology. As the CSF-based ratio of $p$-tau/A $\beta_{42}$ quantifies the concentrations of the two proteinopathies in the CSF, with elevated levels representing higher pathological load, we only examined the high pathology network PATH-fc model in this study. Moreover, as we note below, the low pathology network, did not reach statistical significance and resulted in a total of 2 edges, thus corroborating our a priori decision of not including the low pathology network in our final model. We found that the overall CPM model successfully predicted AD pathology scores $\left(r_{s}=0.32, p=0.028,1000\right.$ iteration permutation testing). Additionally, the high pathology model, the PATH-fc model, comprising of 581 edges (Figure 2A \& B), successfully predicted AD pathology $\left(r_{s}=0.25, p=\right.$ $0.013,1000$ iteration permutation testing; Figure $2 C$ ). However, the predictability of $A D$ pathology in the low pathology model did not reach statistical significance $\left(r_{s}=0.07, p=0.27,1000\right.$ iteration permutation testing). The low pathology model comprised of 2 edges. Thus, in all subsequently reported results, we focus only on the high pathology model.

PATH-fc Model is Predictive of Cognitive Decline: Having established that resting-state functional connectivity predicts AD pathology, we next examined whether the PATH-fc model would predict decline in cognitive functioning in $\mathrm{MCl}$ and $\mathrm{AD}$ individuals. To address this aim, the CPM pipeline was modified to predict the rate of cognitive decline using high pathology model strength. To evaluate the performance of the PATH-fc model in predicting cognitive decline, we then correlated the predicted and observed rates of cognitive decline over a twoyear period on PACC, ADNI-MEM, and ADNI-EF. We found that models trained on PATH-fc strength were able to significantly predict PACC slope $\left(r_{s}=0.25, p=0.02\right)$ and ADNI-EF slope $\left(r_{s}=0.25, P=0.03\right)$, but not ADNI-MEM slope $\left(r_{s}=0.09, p=0.1\right)$. Figure $2 \mathrm{C}$ presents the correlation plots demonstrating the fit between predicted and observed cognitive decline. Similar results were observed when PATH-fc strength scores were correlated with observed rates of cognitive decline (Supplementary Figure S3A).

PATH-fc is a Highly Distributed Model, and Primarily Features Inter-Network Edges: PATH-fc is a highly distributed model, with the 581 edges of the model distributed across all ten macroscale regions (see Materials 
medRxiv preprint doi: https://doi.org/10.1101/2021.01.13.21249597; this version posted January 21, 2021. The copyright holder for this preprint (which was not certified by peer review) is the author/funder, who has granted medRxiv a license to display the preprint in perpetuity.

All rights reserved. No reuse allowed without permission.

and Methods). 483 edges were in the left hemisphere and included 179 ipsilateral connections and 304 contralateral connections. In contrast, 402 edges included were in the right hemisphere, with 98 ipsilateral connections. Within the left hemisphere, nodes with the greatest number of edges were localized to the prefrontal cortex, the parietal cortex, and the limbic. In the right hemisphere, the nodes of the PATH-fc model were more distributed within the parietal cortex, the limbic regions, and the occipital cortex.

Additionally, the 581 edges of the PATH-fc model also included inter- and intra-network edges from nearly all of the 10 canonical networks (Figure 3A). The motor network, default mode network, and frontoparietal network were the three most commonly represented networks within the PATH-fc model (Figure 3A). However, to account for network size in the Shen parcellation scheme, we normalized edge counts using the following formula, as described previously (39):

$$
\text { Contribution }_{A, B}=\frac{m_{A, B} / m_{t o t}}{E_{A, B} / E_{t o t}}
$$

where Contribution $n_{A, B}$ represents the relative contribution of edges between networks $A$ and $B, m_{A, B}$ is the number of edges between $A$ and $B$ in our model, $m_{\text {tot }}$ is the total number of edges in our model, $E_{A, B}$ is the number of possible edges between $A$ and $B$, and $E_{\text {tot }}$ is the total number of possible edges in the whole brain. As shown in the matrix in Figure 3B, accounting for network size demonstrates the relatively high contribution of the default mode network and reduces the prominence of the motor network. The top three networks by relative contribution are the default mode (mean contribution=1.97), visual association (left middle occipital gyrus; mean contribution=1.40), and frontoparietal (left superior frontal gyrus; mean contribution=1.30) networks.

Additionally, we were interested in examining if PATH-fc primarily featured intra-network or inter-network connections. Of the 581 edges, 39 were intra-network edges and 542 edges were inter-network connections. Applying the same contribution formula to these edges shows a higher relative contribution of inter-network edges compared to intra-network edges (average inter-network contribution $=1.051$, average intra-network contribution: 0.5959).

Outlier analysis indicated that four nodes had an elevated number of edges within PATH-fc (Figure 3C). The top two nodes with the most edges in PATH-fc were nodes in the left and right posterior cingulate cortex (PCC) (left MNI coordinates = -6.5, -53.9, 37.4; right MNI coordinates =6.2, -57.4, 38.2); major hubs in the default mode network. $18.76 \%$ of edges in PATH-fc included one of these two nodes. The third and fourth nodes with the most edges were in the visual association (MNI coordinates: $-28.4,-62.3,40.4)$ and salience (MNI coordinates $27.3,34.1,36.4)$ networks.

AD Pathological Models are Robust to Key Confounds: When using additional edge-selection threshold values of $0.1,0.05,0.005$, and 0.001 (40), we observed that model performance was comparable across all thresholds (Supplementary Table S1). Replicating our analyses with an additional functional brain atlas (Glasser360), we found that high pathology model successfully predicted AD pathology (Supplementary Figure $\mathrm{S} 2 \mathrm{~A})$. We next examined whether this newly derived high pathology model would also predict rates of cognitive decline in a similar fashion as our main analysis. We found a significant prediction for PACC scores (Supplementary Figure S2B) and a marginally significant prediction for ADNI-MEM scores (Supplementary Figure $\mathrm{S} 2 \mathrm{C}$ ). However, the prediction for ADNI-EF scores did not reach statistical significance (Supplementary Figure S2D). We also observed that the correlations of PATH-fc predicted AD pathology scores or PATH-fc network strength with the estimated rates of decline on PACC and ADNI-EF, but not ADNI-MEM, were significant (Supplementary Figure S3B). Taken together, these findings suggest that the PATH-fc model was robust to potential confounds.

\section{Discussion}

The goal of this study was to leverage methodological developments in the field of computational neuroscience to derive a whole-brain marker of synchronous neural activity using CSF-based biomarkers of $A D$ pathology. Using connectome-based predictive modeling that captures variance distributed across the brain (32, 33), we derived the PATH-fc model - a highly distributed network of edges with representation across the various macroscale regions - to predict variance in the ratio of $p$-tau/A $\beta_{42}$ in $\mathrm{MCl}$ and $A D$ individuals. The PATH-fc model, consistent with existent literature on the spatial distribution of amyloid $(21,41)$ and tau pathology $(42)$ in $\mathrm{MCl}$ and $A D$ individuals, included all ten canonical networks, with nodes in the default mode network, the frontoparietal network, and the visual association network showing the highest degree of representation. Critically, the PATH-fC model, in addition to predicting AD pathology, predicted the rates of cognitive decline, notably on measures of global cognition and executive functioning. This study is the first to employ computational models of functional connectivity to build a pathology-based model with implications for cognitive decline in AD. 
medRxiv preprint doi: https://doi.org/10.1101/2021.01.13.21249597; this version posted January 21, 2021. The copyright holder for this preprint (which was not certified by peer review) is the author/funder, who has granted medRxiv a license to display the preprint in perpetuity.

All rights reserved. No reuse allowed without permission.

Aggregation of extra-cellular amyloid plaques and intra-cellular neurofibrillary tangles containing hyperphosphorylated tau are the defining pathological features of $A D(2,43,44)$. CSF- and PET-based biomarkers of $A \beta$ and tau have been reliably found to differentiate between healthy and pathological aging (4547 ), predict conversion of $\mathrm{MCl}$ individuals to $A D(48)$, and explain variance in clinical symptoms of dementia (49). However, the accumulation of $A \beta$-plaques and neurofibrillary tangles follow differentiated spatiotemporal trajectories, with amyloid biomarkers representing one of the earliest signs of $A D$ neuropathological changes (50, 51 ), and accumulation of tau inclusions a necessary pathological marker for AD diagnosis (2). Critically, of the various biomarkers of $A D$-based pathology, the CSF-based ratio of $p$-tau/A $\beta_{42}$ provides one of the best diagnostic accuracies among fluid- and PET imaging-based biomarkers $(52,53)$, shows the largest effect sizes, compared with $A \beta_{42}$ or $p$-tau alone in distinguishing between cognitively normal, $M C l$, and $A D$ individuals (54), and predicts performance on the Clinical Dementia Rating Scale (55), measures of driving performance (56), and neuropsychological-based measures of global cognition, memory, executive functioning, and semantic fluency $(54,57)$. As such, in our study, we employed this combined ratio of $p$-tau/A $\beta_{42}$ to derive a whole-brain, functional connectivity marker of AD pathology that would allow us to capture the distinct spatial affinities of the two proteinopathies. Although it would be interesting to also examine networks predicting $A \beta_{42}$ and $p$-tau separately, we were interested in deriving one connectome-based marker that would comprehensively capture the disruptions in large-scale functional networks because of the synergistic effect of accumulating $\beta$-amyloid and tau. Our results, demonstrating successful in-sample fit of the PATH-fc model in predicting $p$-tau/A $\beta_{42}$, provide support for the use of computational modeling techniques in deriving functional connectivity-based models for biological signatures of $A D$ pathology.

The PATH-fc model, derived using a synergistic metric of the two hallmark AD proteinopathies, is a distributed model that includes representation from all macroscale regions and the ten canonical networks. As this model was derived in $\mathrm{MCl}$ and $\mathrm{AD}$ individuals, these results are consistent with in vivo and in vitro studies that implicate the involvement of large swaths of the neocortex in AD pathogenesis, especially in the later stages of the disease when clinical symptoms have already manifested (58-62). The deposition of AD pathology, specifically tau depositions, is hypothesized to spread in a prion-like manner, with pathology often originating in densely connected nodes of the human brain, like the PCC/precuneus and the entorhinal cortices, and spreading trans-neuronally to other highly functionally connected regions, thus engulfing many of the large canonical networks (63-65). Confirming the involvement of large-scale functional networks, the PATH-fc model included 581 edges, with the frontoparietal, default mode, motor, visual I, visual association, and salience networks showing large contributions relative to their network size in the overall model.

Interestingly, a qualitative examination of the involvement of various canonical networks in the PATH-fC model, provides a striking overlap with the spatial affinities of amyloid and tau pathology, which include the densely connected nodes of the default mode network $(41,63)$ and the entorhinal cortices $(64,66)$ respectively. Specifically, PET studies have shown the aggregation of misfolded amyloid proteins to begin in the nodes of the default mode network, with early stages including the mid-cortical posterior and anterior structures involving the PCC, the precuneus, the ACC, and the medial orbitofrontal gyri, and advanced stages including the limbic and the subcortical regions. Tau deposits, on the other hand, appear to originate in the transentorhinal cortices, with pathology spreading in a prion-like manner to areas of the perirhinal cortex, including the hippocampus, the limbic areas, and then widely to the association cortices. These spatial affinities of $A \beta$ and tau-based tangles to target distinct brain regions also mirrors the findings of multi-modal investigations that associate regional binding of PET-based tracers to disruptions in resting-state functional connectivity of large-scale canonical networks (63, 67-70). For example, Elman et al. (63) examined the associations between global and regional PiB retention in cognitively normal older adults and functional connectivity of the canonical networks during rest. Both global and regional $\mathrm{PiB}$ retention was associated with reduced within-network connectivity of nodes in the default mode network, with amyloid pathology also influencing the connectivity of other large-scale networks supporting exogenous attention, like the dorsal attention network and the frontoparietal network. Moreover, they also showed reduced anti-correlations between nodes of the frontoparietal and dorsal attention network and the precuneus, suggesting that the disruptions caused by AD pathology extend beyond intra-network connections, and influence the connectivity of the default mode network with other networks of the brain.

Our results, consistent with the existent literature, highlight the nodes of the default mode network in the PATH-fc model, with both intra-network and inter-network connections of the default mode network predicting $p$ $\operatorname{tau} / A \beta_{42}$ ratio. This result also aligns with other studies examining the association between CSF-based measures of $A D$ pathology and functional connectivity, such that lower levels of $A \beta_{42}$ and $p$-tau are associated with decreased connectivity within nodes of the default mode network, but also extends to interactions between the default mode network and the salience, frontoparietal, and language networks (71). Our study, however, goes beyond establishing correlations between CSF-based measures of AD pathology and functional connectivity, and generates a predictive marker of whole-brain functional connectivity that critically implicates the default mode network as the hub of AD pathology-based disruptions in functional connections. Moreover, two of the four nodes 
medRxiv preprint doi: https://doi.org/10.1101/2021.01.13.21249597; this version posted January 21, 2021. The copyright holder for this preprint (which was not certified by peer review) is the author/funder, who has granted medRxiv a license to display the preprint in perpetuity.

All rights reserved. No reuse allowed without permission.

showing the highest degree - the number of connections a node has with other nodes - were in the default mode network and included both the left and right precuneus. Pathological and PET-based studies further show that these regions are hubs of metabolic activity $(72,73)$, demonstrate aerobic glycolysis $(74,75)$, and show regional reductions in glucose metabolism $(76,77)$, thus potentially making them particularly vulnerable to deposition of AD pathology.

Interestingly, the PATH-fc model, in addition to capturing the involvement of the default mode network, also implicated the involvement of several other networks, most notably the frontoparietal and the visual association networks, with connections between the default mode network and the visual association cortices showing the highest relative contribution to the PATH-fc model. These results support previous PET-fMRI and animal studies implicating the association cortices as potentially key regions involved in the trans-neuronal spread of AD pathology likely via their shared neuronal activity. In-vitro animal studies evince support for the spreading of pathogenic tau via axonal connections to anatomically connected, yet spatially remote regions rather than adjacent regions $(58,59)$. Similarly, human PET-fMRI studies show that the pattern of functional connectivity is associated with tau covariance such that regions with high levels of tau show high functional coupling and those with low regions of tau depositions are coupled with other nodes with low accumulation (67). Importantly, this covariance between functional connectivity and tau deposition was independent of the Eucledian distance between the regions, suggesting that tau propagation was dependent on the synaptic connectivity rather than spatial adjacency. This covariance between tau spread in highly connected regions is also independent of overall functional connectivity of the cortex given that tau accumulation is inversely associated with overall functional connectivity (68), thus suggesting that higher neuronal coupling of spatially distant, yet connected regions results in spread of AD pathology from cell-to-cell in large-scale structurally and functionally connected networks.

Collectively, the results of our study and other human multi-modal investigations, highlight the covariance between accumulation of pathological proteins and disruptions of synchronous neuronal activity within and between canonical networks. In fact, it is widely appreciated that these disruptions antedate the appearance of clinical symptoms, and although there are equivocal findings with regards to associations between individual pathological markers and clinical symptomatology, combined metrics of amyloidosis and tauopathy are more consistently associated with declining cognitive functioning. Within the ADNI dataset, we have demonstrated that $\mathrm{p}$-tau/A $\beta_{42}$ ratio predicts the two-year slope of cognitive decline on composite measures of global cognition, executive functioning, and episodic memory in 619 individuals with $\mathrm{MCl}$ and 229 older adults with AD (54). Extending the current literature evincing support for associations between pathological and clinical metrics of AD, in this study, we demonstrate that the PATH-fc model derived to predict $p$-tau/A $\beta_{42}$ ratio can also successfully predict the change in cognitive functioning, specifically on measures of global cognition and executive functioning. These results, although cross-sectional in nature, imply that our computational model of pathology-dependent functional connectivity predicts changes in measures of global cognition and executive functioning in $\mathrm{MCl}$ and $\mathrm{AD}$ individuals over the course of two years. Thus, although previous studies have demonstrated associations between disruptions in functional connectivity and cognitive functioning, and pathology-based biomarkers of $A D$ pathology and cognition, our study provides support for AD pathology dependent functional connectivity disturbances in large-scale functional networks to influence the trajectory of key cognitive domains in $\mathrm{MCl}$ and $\mathrm{AD}$ patients.

It is important to consider the results and interpretations of this study in the context of certain limitations. First, to derive a model of AD pathology, we employed the CSF-based p-tau/AB42 ratio, with this metric representing a summary measure of fluid-based pathology. This ratiometric measure, however, lacks the spatial specificity that could be derived from PET-based markers of AD pathology, thus resulting in a connectome model that may be qualitatively different from one generated using regionally-specific PET amyloid and tau ligands. Although not ideal, CSF-based markers are more readily available in publicly available longitudinal datasets; have strong diagnostic accuracies (14-16); and have been associated with aberrant FC in large-scale canonical networks (78). Additionally, CPM methodology is able to identify connections that are most important for linking FC to the desired behavior or characteristic, thus identifying connections between nodes that are linked to this global summary measure of pathology. Future studies, integrating across PET and fMRI, may be able to create joint connectome models that concatenate regional update of PiB and tau tracers with functional connectivity estimates to build spatially-specific pathology-based models.

Second, although the PATH-fc model predicted the rate of cognitive decline over a two-year period, because of attrition in the ADNI dataset that differed as a function of diagnostic group, we did not include more longitudinal follow-up assessments. To validate the model for predicting clinically meaningful cognitive decline, it would be important to demonstrate the utility of this connectome-based model in predicting conversion of diagnostic status, either from cognitively normal to $\mathrm{MCl}$, or from $\mathrm{MCl}$ to $\mathrm{AD}$. As such, although there is promise in this pathology-dependent functional connectivity marker for cognitive functioning of $\mathrm{MCl}$ and $\mathrm{AD}$ individuals, it would be critical to extend this model beyond the current results. 
medRxiv preprint doi: https://doi.org/10.1101/2021.01.13.21249597; this version posted January 21, 2021. The copyright holder for this preprint (which was not certified by peer review) is the author/funder, who has granted medRxiv a license to display the preprint in perpetuity.

All rights reserved. No reuse allowed without permission.

And, finally, our study was predominantly cross-sectional in nature, and although we used computational predictive modelling to derive a pathology-dependent marker, longitudinal investigations would be needed to assess the impact of pathology progression on large-scale networks.

Overall, in the last 10 years, great strides have been made in our understanding of this clinicalpathological neurodegenerative disease, with clear consensus that sensitive and specific biomarkers are critically needed for refining diagnostic accuracy, predicting progression of the disease, and identifying preventative and therapeutic treatments. Our results provide support for use of functional connectivity measures to build a model that is predictive of hallmark $A D$ pathology and cognitive consequences of the structural and functional alterations. Future studies, validating this model in external datasets to predict pathology and conversion of diagnostic status, are needed to determine the utility of this model.

\section{Materials and Methods}

Participants and Experimental Design: The current study is a secondary analysis of publicly available data from The Alzheimer's Disease Neuroimaging Initiative (ADNI). ADNI is a multicenter study designed to assess AD progression, collecting longitudinal, multi-modal data involving MRI, PET, CSF- and plasma-based biological markers, and detailed neuropsychological measures. Inclusionary criteria for participants in the ADNI dataset involved the following requirements: aged between 55-90 years, overall good health condition, fluent in either English or Spanish, and geriatric depression scale score of less than six. We used the ADNIGO and ADNI2 phases since ADNI1 and ADNI3 do not have matching MRI parameters, and ADNI3 is still being collected. 200 individuals with $\mathrm{MCl}$ were collected as part of ADNIGO, with an additional 400 AD pathology individuals (150 AD, $250 \mathrm{MCl}$ ) collected as part of ADNI2. However, resting-state data was only collected at a limited number of sites, leaving 100 (49\% Female) participants who had baseline fMRI data: 76 are individuals with mild cognitive impairment $(\mathrm{MCl})$, and 24 are individuals with $A D$.

Diagnostic criteria for classifying participants on the spectrum of pathological aging at baseline involved a combination of subjective reports, neuropsychological assessment, and physician assessment (79). Specifically, for $\mathrm{MCl}$ participants, the following criteria were employed: 1) MMSE score $\geq 24,2$ ) scoring within educationadjusted range for the Logical Memory II subscale (EMCl: 9-11 for 16+ years of education, 5-9 for 8-15 years of education, 3-6 for 0-7 years of education; LMCl: $\leq 8$ for $16+$ of education, $\leq 4$ for 8-15 years of education, $\leq 2$ for 0-7 years of education), 3 ) a Clinical Dementia Rating score of $0.5,4$ ) self or partner reported memory complaint(s), and 5) absence of AD dementia or any other neurological condition. AD participants were required to meet the following criteria: 1) MMSE score between 20-26, 2) scoring below education-adjusted cut-offs for the Logical Memory Scale II ( 8 for $16+$ of education, $\leq 4$ for 8-15 years of education, $\leq 2$ for 0-7 years of education), 3 ) a Clinical Dementia Rating score of 0.5 or 1.0 , and 4 ) self or partner reported memory complaints.

Of the 100 participants initially identified from the ADNI dataset, participants without biomarker data $(n$ $=4$ ), with excessive head motion, defined as mean framewise displacement $>.15 \mathrm{~mm}(n=10)$, and those with poor whole-brain coverage $(n=3)$ were excluded. Data from the remaining 83 participants were used for all analyses.

CSF Biomarker Assessment and Classification: CSF biomarker concentrations were pulled from the upennbiomk9.rdata file nested in the ADNIMERGE R package. The upennbiomk9.rdata file includes CSF biomarker concentrations from ADNI's first 3 recruitment waves: ADNI1, ADNI-GO, and ADNI2. P-tau and A $\beta_{42}$ concentrations were measured in picograms per milliliter $(\mathrm{pg} / \mathrm{mL})$ by ADNI researchers using the highly automated Roche Elecsys immunoassays on the Cobas e601 automated system. In this study, we used concentrations measured by the Roche Elecsys assay over those measured by the traditional AlzBio3 immunoassay platform as the Roche Elecsys system is the primary assay for ADNl's current recruitment wave (ADNI3), thus allowing for current analyses and results to be compatible with studies that will utilize future ADNI data releases.

The Elecsys-based assay has a lower and upper measurement limit for $A \beta_{42}$ concentrations (200-1700 $\mathrm{pg} / \mathrm{ml}$ ). Although there were no extrapolated values provided for the lower limit values, extrapolated values for the upper limit, based on calibration curves, and provided by the ADNI group were employed for the current analysis. Of the 83 participants, 13 participants met the upper limit for the $A \beta_{42}$ concentration. For all participants, we computed the ratiometric measure of $p$-tau/ $A \beta_{42}$, with higher values representing higher pathological state of the two proteinopathies.

Neuropsychological Measures and Composites: Participants in the ADNI study were administered detailed neuropsychological batteries to examine the following cognitive domains: global cognition, episodic memory, executive functioning, spatial orientation, processing speed, and language. In this study, we focused our analyses on three cognitive domains that are commonly impacted in AD: global cognition, episodic memory, and executive 
medRxiv preprint doi: https://doi.org/10.1101/2021.01.13.21249597; this version posted January 21, 2021. The copyright holder for this preprint (which was not certified by peer review) is the author/funder, who has granted medRxiv a license to display the preprint in perpetuity.

All rights reserved. No reuse allowed without permission.

functioning. This a priori decision was also driven by the availability of pre-existing, validated composites for the three cognitive domains that sum performance across multiple metrics to yield a summary score.

Measures assessing changes in global cognition tend to be the strongest predictors for conversion to $A D$ (80), and also correlate significantly with clinical symptoms of dementia (81). We employed the Preclinical Alzheimer's Cognitive Composite Score (PACC) designed to characterize the presence of global cognitive deficits in preclinical $A D$ as one of the cognitive outcome variables in the study. The composite summarizes performance across the domains of episodic memory, executive functioning, and overall cognition, and includes the following measures: Mini-Mental Status Examination total score, Trails-Making Test B, delayed recall score from the Logical Memory II subscale, and the delayed word recall from the Alzheimer's Disease Assessment ScaleCognitive Subscale (ADAS-COG). PACC scores were provided in the adnimerge.rdata file for baseline, 6-months, 12-months, and 24-months.

To index changes in episodic memory over a two-year period, we employed the ADNI-MEM composite. This composite includes performance on the Logical Memory I and II tasks, several item scores on the Rey Auditory Verbal Learning Test, the cognitive subscale of the Alzheimer's Disease Assessment Scale, and the three word recall items from the Mini-Mental State Examination (82). For executive functioning, we employed the ADNI-EF composite developed in the ADNI sample using item response theory. The ADNI-EF composite includes performance on the Digit Symbol Substitution test from the Weschler Adult Intelligence Scale-Revised, Digit Span Backwards Test, Trails-Making A and B, Category Fluency, and Clock Drawing (83). ADNI-EF has been shown to be a stronger predictor of $A D$ conversion than its component measures and has been associated with dichotomized CSF concentrations (83).

ADNI-MEM and ADNI-EF were pulled from the uwnpsychsum.rdata file nested in the ADNIMERGE R package. Although ADNI has longer-term follow-up data, there is significant attrition as a function of the diagnostic group, such that at 36 months follow-up, only $53 \mathrm{MCl}$ individulals had CSF data, neuroimaging, and neuropsychological data and there were no participants with $A D$ with all of these data at 36 months.

MRI Data Acquisition: Structural and functional MRI data, included in the current study, was acquired using a 3 Tesla Phillips Medical Systems MRI scanner. Each participant's T1-weighted 3D (TR $=6.7 \mathrm{~ms}, \mathrm{TE}=3.1 \mathrm{~ms}$, flip angle $=9^{\circ}$, field of view $=256 \times 256 \times 170-\mathrm{mm}^{3}$, slice thickness $=1.20-\mathrm{mm}$, voxel size standard $=1.0-\mathrm{mm}^{3}$, voxel size accelerated $=1.11 \mathrm{~mm}^{3}, 170$ sagittal slices) was included in the study. A total of 140 volumes of resting-state $\mathrm{fMRI}$ data were acquired using the following acquisition parameters: $\mathrm{TR}=3000 \mathrm{~ms}$, TE $=30 \mathrm{~ms}$, flip angle $=80^{\circ}$, field of view $=212 \times 212-\mathrm{mm}^{2}$, slice thickness $=3.13-\mathrm{mm}$, voxel size $=3.125-\mathrm{mm}^{3}, 48$ sagittal slices. Five participants had a TR (repetition time) of $2.25 \mathrm{~ms}$. However, we accounted for this discrepancy by using subjectspecific TR for all data preprocessing and postprocessing steps that required specifying the TR. All downloaded structural and functional MRI data from the ADNI were first converted from DICOM to NIFTI format and organized according to the Brain Imaging Data Structure (BIDS) (84) and processed through validated quality control pipeline that provide an initial assessment of signal-to-noise (SNR) ratio, framewise displacement (FD), and overall drift rate of signal (85).

MRI Data Preprocessing: Preprocessing of anatomical and functional data was carried out using fMRIPrep v1.4.1 (86). Each participant's T1w image was corrected for intensity non-uniformity with N4BiasFieldCorrection (87) and skull-stripped with a Nipype implementation of the antsBrainExtraction.sh. Brain surfaces were then reconstructed using recon-all from FreeSurfer v6.0.1(88) and spatially normalized to MNI space through nonlinear registration with antsRegistration tool (89). Brain tissue segmentation of CSF, white-matter (WM) and gray-matter (GM) was performed on the brain-extracted T1w using fast in FSL v5.0.9.

Functional data was slice time corrected using 3dTshift from AFNI (90), motion corrected using mcflirt (91), and co-registered to the corresponding T1w using boundary-based registration (92) with nine degrees of freedom (using bbregister in FreeSurfer v6.0.1). Motion correcting transformations, BOLD-to-T1w transformation, and T1w-to-template (MNI) warp were concatenated and applied in a single step with antsApplyTransforms (ANTs v2.1.0) using Lanczos interpolation. Physiological noise regressors were extracted based on CompCor procedure (93). Several confounding timeseries, including FD and global signal (94), were calculated based on the functional data using the implementation of Nipype. Many internal operations of fMRIPrep use Nilearn (95), principally within the BOLD-processing workflow. For more details of the pipeline see: https://fmriprep.readthedocs.io/en/latest/workflows.html.

Following data preprocessing in fMRIPrep, we excluded the first 3 volumes of each functional data to allow BOLD signal stabilization. We then used signal.clean in Nilearn (95) to remove the following potential confounding sources of signal variance: mean CSF signal, mean WM signal, mean global signal, and a 24parameter motion model (i.e. six rigid body motion parameters, six temporal derivatives and their squares,(96)), and linear trend. To further control for potential motion related confounds, we added a spike regressor for each 
medRxiv preprint doi: https://doi.org/10.1101/2021.01.13.21249597; this version posted January 21, 2021. The copyright holder for this preprint (which was not certified by peer review) is the author/funder, who has granted medRxiv a license to display the preprint in perpetuity.

All rights reserved. No reuse allowed without permission.

frame with FD value $\geq 0.5 \mathrm{~mm}$ (97). Functional data was highpass-filtered in the temporal domain to remove frequency signals less than $0.01 \mathrm{~Hz}$. No spatial smoothing of functional data was performed (98).

Whole-Brain Parcellation and Functional Connectivity Estimation: The preprocessed resting-state data for each participant was parcellated into 268 contiguous, functionally defined regions using the Shen parcellation scheme covering the cortex, subcortex, and cerebellum(99). The functional atlas was transformed from MNI space to each participant's native space. BOLD signal timecourses from each region were extracted by averaging all voxels in that region. The connections between each pair of these brain regions or nodes, defined as edges, were computed by correlating the timecourse of activity between the nodes using Pearson's correlations. Prior to applying Fisher z-transformation to functional connectivity data, we excluded 5 nodes from all subjects as they were missing in 3 or more subjects. These nodes were in the cerebellar (2), prefrontal (1), temporal (1) regions and Brainstem (1), resulting in a 263X263 FC matrix for each participant, with cells of the matrix representing the magnitude of these edges or correlations.

\section{Connectome-Based Predictive Modeling:}

Derivation of PATH-fC functional connectivity model: Figure 1 presents the schematic representation of the various steps of CPM. First, this model employs a leave-one-out-cross-validation (LOOCV) procedure, wherein the data is divided into a training set ( $\mathrm{n}-1$ participants) and a test set, with this process repeated until each participant has served as the test participant (Figure 1A). To define an AD pathology network, for all participants in the training set, each cell of the functional connectivity matrix was correlated with $p$-tau/A $\beta_{42}$ and thresholded for significant correlations, across participants, at $p<.01$ (Figure 1B), resulting in a set of edges where each surviving edge is either positively or negatively associated with CSF-biomarker accumulation (Figure 1C). To further reduce the effect of motion, we regressed out the mean FD values for each participant at this edge-selection step. As noted above, we only examined the high pathology network showing edges positively correlated with CSF-biomarker accumulation. This CPM technique thus yields predicted AD pathology scores for each participant (Figure 1D), which are then correlated using Spearman's rank correlation $(\rho)$ with observed scores to generate a measure of model performance (Figure 1E).

Permutation testing, involving shuffling observed AD pathology scores and implementing CPM LOOCV 1000 times to build a null distribution, was employed to evaluate if the prediction performance for the PATH-fc model was significantly better than expected by chance. We also ran permutation testing for each validation analysis described below.

Application of PATH-fc model to predict cognitive decline: Changes in cognitive outcomes (PACC, ADNI-MEM, and ADNI-EF) over time were modeled using linear mixed effects models. We estimated the rate of change over two years by modeling performance at baseline, 6-months, 12-months, and 24-months using a mixed model that included fixed effects of time (linear), diagnosis group, and their interaction. From this model the empirical best linear unbiased predictor (eBLUP) for each subject was estimated and used as the subject-specific measure of cognitive decline. In order to determine whether our AD pathology network could also be used to predict rate of cognitive decline in an unseen individual, we employed the averaged connectivity strength within the PATH-fC high network to train three predictive models for rate of cognitive decline on the PACC, ADNI-MEM, and ADNI-EF, each evaluated using a LOOCV approach.

Anatomical and Network Localization of PATH-fc Model: Edges were deemed reliable if they appeared in every round of LOOCV iterations across all subjects (39). The final mask, comprising of edges present in every round of the LOOCV, represented the PATH-fc model with 581 edges distributed across all macroscale regions. To summarize the involvement of the macroscale regions as well as the canonical networks, we parcellated the 268 nodes of the Shen atlas based on their spatial overlap with the 10 macroscale regions identified in Finn et al., (100) and the 10 canonical networks identified in (101) (Figure S1). For the macroscale regions, the following anatomical labels were employed: prefrontal, motor, insular, parietal, temporal, occipital, limbic, cerebellum, brainstem, and subcortical. The canonical networks included the following: medial frontal, frontoparietal, default mode, motor, visual I, visual II, visual association, salience, subcortical, and cerebellar networks. For the canonical networks, we summarize the overall involvement of the various networks, but also the relative involvement of each network, adjusted for size (or number of nodes) of the network in both the Shen atlas and the PATH-fc model (39). And, finally, we calculated degree - sum of the number of edges - for each node of the PATH-fc model to highlight nodes that show the highest number of connections with other nodes in this AD pathology-based model. Ring plots were created using Flourish data visualization tools (https://flourish.studio/). BrainNet Viewer toolbox (102) was used for brain-based visualization of the PATH-fc.

Validation Analyses: Choice of feature selection threshold: As the choice of edge threshold selection is inherently arbitrary, we tested the sensitivity and robustness of the PATH-fc model to additional thresholds with $p$-values of 
medRxiv preprint doi: https://doi.org/10.1101/2021.01.13.21249597; this version posted January 21, 2021. The copyright holder for this preprint (which was not certified by peer review) is the author/funder, who has granted medRxiv a license to display the preprint in perpetuity.

All rights reserved. No reuse allowed without permission.

$0.1,0.05,0.005$, and 0.001 (40). Alternative Parcellation Scheme: Previous studies have shown that the specific choice of a parcellation scheme may impact the results from brain network analysis $(103,104)$. To investigate potential parcellation effects, we employed an additional functional atlas consisting of 360 brain regions (Glasser360, (105)). Similar to the main analysis, we estimated mean BOLD timecourses and excluded four nodes (two each in the prefrontal and temporal regions) from all subjects as they were missing in three or more subjects. This resulted in a 356X356 FC matrix for each subject. All analyses described under connectome-based predictive modeling were repeated, including derivation of the PATH-fc model, and application of the PATH-fc model to predict $A D$ pathology and change in cognitive decline.

\section{Acknowledgments}

The project described in this publication was supported by Award Number UL1TR002733 from the National Center For Advancing Translational Sciences and Award Number R01AG054427 from the National Institute On Aging of the National Institutes of Health. The content is solely the responsibility of the authors and does not necessarily represent the official views of the National Center For Advancing Translational Sciences, the National Institute on Aging or the National Institutes of Health.

\section{References}

1. Alzheimer's Association, “Fiscal Year 2020 Alzheimer's Research Funding” (2019).

2. C. R. Jack, et al., NIA-AA Research Framework: Toward a biological definition of Alzheimer's disease. Alzheimers Dement 14, 535-562 (2018).

3. R. A. Sperling, et al., Toward defining the preclinical stages of Alzheimer's disease: recommendations from the National Institute on Aging-Alzheimer's Association workgroups on diagnostic guidelines for Alzheimer's disease. Alzheimers Dement 7, 280-292 (2011).

4. C. M. Hulette, et al., Neuropathological and neuropsychological changes in "normal" aging: Evidence for preclinical Alzheimer disease in cognitively normal individuals. J Neuropathol Exp Neurol 57, 1168-1174 (1998).

5. J. L. Price, J. C. Morris, Tangles and plaques in nondemented aging and "preclinical" Alzheimer's disease. Ann. Neurol. 45, 358-368 (1999).

6. D. A. Bennett, et al., Decision rules guiding the clinical diagnosis of Alzheimer's disease in two communitybased cohort studies compared to standard practice in a clinic-based cohort study. Neuroepidemiology 27, 169-176 (2006).

7. C. C. Rowe, et al., Amyloid imaging results from the Australian Imaging, Biomarkers and Lifestyle (AIBL) study of aging. Neurobiology of Aging 31, 1275-1283 (2010).

8. P. T. Nelson, et al., Modeling the Association between 43 Different Clinical and Pathological Variables and the Severity of Cognitive Impairment in a Large Autopsy Cohort of Elderly Persons. Brain Pathology 20, 66-79 (2010).

9. N. Andreasen, et al., Evaluation of CSF-tau and CSF-Abeta42 as diagnostic markers for Alzheimer disease in clinical practice. Arch. Neurol. 58, 373-379 (2001).

10. I. Baldeiras, et al., Addition of the $A \beta 42 / 40$ ratio to the cerebrospinal fluid biomarker profile increases the predictive value for underlying Alzheimer's disease dementia in mild cognitive impairment. Alzheimers Res Ther 10, 33 (2018).

11. T. T. Seppälä, et al., CSF biomarkers for Alzheimer disease correlate with cortical brain biopsy findings. Neurology 78, 1568-1575 (2012). 
medRxiv preprint doi: https://doi.org/10.1101/2021.01.13.21249597; this version posted January 21, 2021. The copyright holder for this preprint (which was not certified by peer review) is the author/funder, who has granted medRxiv a license to display the preprint in perpetuity.

All rights reserved. No reuse allowed without permission.

12. T. Sunderland, et al., Decreased beta-amyloid1-42 and increased tau levels in cerebrospinal fluid of patients with Alzheimer disease. JAMA 289, 2094-2103 (2003).

13. I.-M. Lee, et al., Association of Step Volume and Intensity With All-Cause Mortality in Older Women. JAMA Internal Medicine 179, 1105 (2019).

14. O. Hansson, et al., Association between CSF biomarkers and incipient Alzheimer's disease in patients with mild cognitive impairment: a follow-up study. Lancet Neurol 5, 228-234 (2006).

15. N. Mattsson, et al., CSF biomarkers and incipient Alzheimer disease in patients with mild cognitive impairment. JAMA 302, 385-393 (2009).

16. S. Palmqvist, et al., Detailed comparison of amyloid PET and CSF biomarkers for identifying early Alzheimer disease. Neurology 85, 1240-1249 (2015).

17. P. Lewczuk, et al., Cerebrospinal Fluid A $\beta 42 / 40$ Corresponds Better than $A \beta 42$ to Amyloid PET in Alzheimer's Disease. J. Alzheimers Dis. 55, 813-822 (2017).

18. R. F. Buckley, et al., Functional network integrity presages cognitive decline in preclinical Alzheimer disease. Neurology 89, 29-37 (2017).

19. A. Badhwar, et al., Multivariate consistency of resting-state fMRI connectivity maps acquired on a single individual over 2.5 years, 13 sites and 3 vendors. Neuroimage 205, 116210 (2019).

20. H. Matsuda, Cerebral blood flow and metabolic abnormalities in Alzheimer's disease. Ann Nucl Med 15, 85 (2001).

21. R. L. Buckner, et al., Cortical hubs revealed by intrinsic functional connectivity: Mapping, assessment of stability, and relation to Alzheimer's disease. The Journal of Neuroscience 29, 1860-1873 (2009).

22. P. Thomas, et al., One year follow-up of a pragmatic multi-centre randomised controlled trial of a groupbased fatigue management programme (FACETS) for people with multiple sclerosis. BMC neurology 14 , 109 (2014).

23. J. P. Chhatwal, et al., Anticholinergic Amnesia is Mediated by Alterations in Human Network Connectivity Architecture. Cerebral Cortex 29, 3445-3456 (2019).

24. K. Wang, et al., Altered functional connectivity in early Alzheimer's disease: A resting-state fMRI study. Human Brain Mapping 28, 967-978 (2007).

25. M. R. Brier, et al., Loss of Intranetwork and Internetwork Resting State Functional Connections with Alzheimer's Disease Progression. J. Neurosci. 32, 8890-8899 (2012).

26. A. P. Schultz, et al., Phases of Hyperconnectivity and Hypoconnectivity in the Default Mode and Salience Networks Track with Amyloid and Tau in Clinically Normal Individuals. J. Neurosci. 37, 4323-4331 (2017).

27. B. B. Biswal, et al., Toward discovery science of human brain function. PNAS 107, 4734-4739 (2010).

28. M. Kaiser, The potential of the human connectome as a biomarker of brain disease. Front. Hum. Neurosci. 7 (2013).

29. D. C. Van Essen, D. M. Barch, The human connectome in health and psychopathology. World Psychiatry 14, 154-157 (2015).

30. M. D. Rosenberg, et al., A neuromarker of sustained attention from whole-brain functional connectivity. Nature neuroscience 19, 165-171 (2016). 
medRxiv preprint doi: https://doi.org/10.1101/2021.01.13.21249597; this version posted January 21, 2021. The copyright holder for this preprint (which was not certified by peer review) is the author/funder, who has granted medRxiv a license to display the preprint in perpetuity.

All rights reserved. No reuse allowed without permission.

31. X. Shen, et al., Using connectome-based predictive modeling to predict individual behavior from brain connectivity. nature protocols 12, 506-518 (2017).

32. M. D. Rosenberg, et al., Methylphenidate modulates functional network connectivity to enhance attention. Journal of Neuroscience 36, 9547-9557 (2016).

33. M. D. Rosenberg, E. S. Finn, D. Scheinost, R. T. Constable, M. M. Chun, Characterizing Attention with Predictive Network Models. Trends in Cognitive Sciences (2017).

34. S. Fountain-Zaragoza, S. Samimy, M. D. Rosenberg, R. S. Prakash, Connectome-based models predict attentional control in aging adults. Neurolmage 186, 1-13 (2019).

35. Q. Lin, et al., Resting-State Functional Connectivity Predicts Cognitive Impairment Related to Alzheimer's Disease. Front. Aging Neurosci. 10 (2018).

36. E. M. Lake, et al., The Functional Brain Organization of an Individual Allows Prediction of Measures of Social Abilities Transdiagnostically in Autism and Attention-Deficit/Hyperactivity Disorder. Biological psychiatry (2019).

37. S. W. Yip, D. Scheinost, M. N. Potenza, K. M. Carroll, Connectome-Based Prediction of Cocaine Abstinence. Am J Psychiatry 176, 156-164 (2019).

38. K. Yoo, et al., Connectome-based predictive modeling of attention: Comparing different functional connectivity features and prediction methods across datasets. Neurolmage 167, 11-22 (2018).

39. A. S. Greene, S. Gao, D. Scheinost, R. T. Constable, Task-induced brain state manipulation improves prediction of individual traits. Nature Communications 9, 2807 (2018).

40. S. Gao, A. S. Greene, R. T. Constable, D. Scheinost, Combining multiple connectomes improves predictive modeling of phenotypic measures. Neurolmage 201, 116038 (2019).

41. R. L. Buckner, et al., Molecular, structural, and functional characterization of alzheimer's disease: Evidence for a relationship between default activity, amyloid, and memory. Journal of Neuroscience 25, 7709-7717 (2005).

42. H. Braak, E. Braak, Demonstration of Amyloid Deposits and Neurofibrillary Changes in Whole Brain Sections. Brain Pathology 1, 213-216 (1991).

43. A. I. Jack, R. E. Boyatzis, M. S. Khawaja, A. M. Passarelli, R. L. Leckie, Visioning in the brain: An fMRI study of inspirational coaching and mentoring. Social Neuroscience 8, 369-384 (2013).

44. C. R. Jack, et al., Brain beta-amyloid measures and magnetic resonance imaging atrophy both predict time-to-progression from mild cognitive impairment to Alzheimer's disease. Brain 133, 3336-3348 (2010).

45. F. H. Duits, et al., The cerebrospinal fluid "Alzheimer profile": Easily said, but what does it mean? Alzheimer's \& Dementia 10, 713-723.e2 (2014).

46. A. M. Fagan, et al., Cerebrospinal Fluid tau/ß-Amyloid42 Ratio as a Prediction of Cognitive Decline in Nondemented Older Adults. Arch Neurol 64, 343-349 (2007).

47. G. Li, et al., CSF tau/Abeta42 ratio for increased risk of mild cognitive impairment: a follow-up study. Neurology 69, 631-639 (2007).

48. B. Olsson, et al., CSF and blood biomarkers for the diagnosis of Alzheimer's disease: a systematic review and meta-analysis. Lancet Neurol 15, 673-684 (2016).

49. C. M. Roe, et al., Improving CSF biomarker accuracy in predicting prevalent and incident Alzheimer disease. Neurology 76, 501-510 (2011). 
medRxiv preprint doi: https://doi.org/10.1101/2021.01.13.21249597; this version posted January 21, 2021. The copyright holder for this preprint (which was not certified by peer review) is the author/funder, who has granted medRxiv a license to display the preprint in perpetuity.

All rights reserved. No reuse allowed without permission.

50. J. Hardy, D. Allsop, Amyloid deposition as the central event in the aetiology of Alzheimer's disease. Trends Pharmacol. Sci. 12, 383-388 (1991).

51. R. J. Bateman, et al., Clinical and Biomarker Changes in Dominantly Inherited Alzheimer's Disease. New England Journal of Medicine 367, 795-804 (2012).

52. O. Hansson, et al., CSF biomarkers of Alzheimer's disease concord with amyloid- $\beta$ PET and predict clinical progression: A study of fully automated immunoassays in BioFINDER and ADNI cohorts.

Alzheimer's \& Dementia 14, 1470-1481 (2018).

53. C. M. Roe, A. M. Fagan, E. A. Grant, D. M. Holtzman, J. C. Morris, CSF biomarkers of Alzheimer disease. Neurology 81, 2028-2031 (2013).

54. R. S. Prakash, et al., p-tau/Aß42 Ratio Associates with Cognitive Decline in Alzheimer's disease, Mild Cognitive Impairment, and Cognitively Unimpaired Older Adults. Under Review.

55. J. Dumurgier, et al., Alzheimer's Disease Biomarkers and Future Decline in Cognitive Normal Older Adults. J. Alzheimers Dis. 60, 1451-1459 (2017).

56. C. M. Roe, et al., Preclinical Alzheimer's disease and longitudinal driving decline. Alzheimer's \& Dementia: Translational Research \& Clinical Interventions 3, 74-82 (2017).

57. A. Soldan, et al., Hypothetical Preclinical Alzheimer Disease Groups and Longitudinal Cognitive Change. JAMA Neurol 73, 698-705 (2016).

58. M. Iba, et al., Synthetic Tau Fibrils Mediate Transmission of Neurofibrillary Tangles in a Transgenic Mouse Model of Alzheimer's-Like Tauopathy. J Neurosci 33, 1024-1037 (2013).

59. F. Clavaguera, et al., Transmission and spreading of tauopathy in transgenic mouse brain. Nature Cell Biology 11, 909-913 (2009).

60. L. Zhou, et al., Plasma amyloid- $\beta$ oligomers level is a biomarker for Alzheimer's disease diagnosis. Biochemical and Biophysical Research Communications 423, 697-702 (2012).

61. W. R. Markesbery, Neuropathologic Alterations in Mild Cognitive Impairment: A Review. Journal of Alzheimer's Disease 19, 221-228 (2010).

62. H. I. L. Jacobs, et al., The cerebellum in Alzheimer's disease: evaluating its role in cognitive decline. Brain 141, 37-47 (2018).

63. J. A. Elman, et al., Effects of Beta-Amyloid on Resting State Functional Connectivity Within and Between Networks Reflect Known Patterns of Regional Vulnerability. Cereb Cortex 26, 695-707 (2016).

64. S. K. Kaufman, K. Del Tredici, T. L. Thomas, H. Braak, M. I. Diamond, Tau seeding activity begins in the transentorhinal/entorhinal regions and anticipates phospho-tau pathology in Alzheimer's disease and PART. Acta Neuropathol 136, 57-67 (2018).

65. L. D. Evans, et al., Extracellular Monomeric and Aggregated Tau Efficiently Enter Human Neurons through Overlapping but Distinct Pathways. Cell Rep 22, 3612-3624 (2018).

66. J. N. Adams, S. N. Lockhart, L. Li, W. J. Jagust, Relationships Between Tau and Glucose Metabolism Reflect Alzheimer's Disease Pathology in Cognitively Normal Older Adults. Cereb Cortex 29, 1997-2009 (2019).

67. N. Franzmeier, et al., Functional connectivity associated with tau levels in ageing, Alzheimer's, and small vessel disease. Brain 142, 1093-1107 (2019). 
medRxiv preprint doi: https://doi.org/10.1101/2021.01.13.21249597; this version posted January 21, 2021. The copyright holder for this preprint (which was not certified by peer review) is the author/funder, who has granted medRxiv a license to display the preprint in perpetuity.

All rights reserved. No reuse allowed without permission.

68. T. E. Cope, et al., Tau burden and the functional connectome in Alzheimer's disease and progressive supranuclear palsy. Brain 141, 550-567 (2018).

69. T. Hedden, et al., Disruption of Functional Connectivity in Clinically Normal Older Adults Harboring Amyloid Burden. J. Neurosci. 29, 12686-12694 (2009).

70. Y. I. Sheline, et al., APOE4 allele disrupts resting state fMRI connectivity in the absence of amyloid plaques or decreased CSF AB42. The Journal of Neuroscience 30, 17035-17040 (2010).

71. M. Weiler, G. Northoff, B. P. Damasceno, M. L. F. Balthazar, Self, cortical midline structures and the resting state: Implications for Alzheimer's disease. Neuroscience \& Biobehavioral Reviews 68, 245-255 (2016).

72. W. J. Jagust, E. C. Mormino, Lifespan brain activity, $\beta$-amyloid, and Alzheimer's disease. Trends Cogn. Sci. (Regul. Ed.) 15, 520-526 (2011).

73. S. Saxena, P. Caroni, Selective neuronal vulnerability in neurodegenerative diseases: from stressor thresholds to degeneration. Neuron 71, 35-48 (2011).

74. S. N. Vaishnavi, et al., Regional aerobic glycolysis in the human brain. Proceedings of the National Academy of Sciences 107, 17757-17762 (2010).

75. A. G. Vlassenko, et al., Spatial correlation between brain aerobic glycolysis and amyloid- $\beta$ (A $\beta$ ) deposition. Proceedings of the National Academy of Sciences (2010) https:/doi.org/10.1073/pnas.1010461107.

76. G. E. Alexander, K. Chen, P. Pietrini, S. I. Rapoport, E. M. Reiman, Longitudinal PET Evaluation of Cerebral Metabolic Decline in Dementia: A Potential Outcome Measure in Alzheimer's Disease Treatment Studies. AJP 159, 738-745 (2002).

77. J. B. S. Langbaum, et al., Categorical and correlational analyses of baseline fluorodeoxyglucose positron emission tomography images from the Alzheimer's Disease Neuroimaging Initiative (ADNI). Neuroimage 45, 1107-1116 (2009).

78. X. Li, et al., Ratio of Aß42/P-tau181p in CSF is associated with aberrant default mode network in AD. Sci Rep 3, 1339 (2013).

79. R. C. Petersen, et al., Prevalence of mild cognitive impairment is higher in men. Neurology 75, 889-897 (2010).

80. M. C. Donohue, et al., The preclinical Alzheimer cognitive composite: measuring amyloid-related decline. JAMA Neurol 71, 961-970 (2014).

81. E. C. Mormino, et al., Early and late change on the preclinical Alzheimer's cognitive composite in clinically normal older individuals with elevated amyloid $\beta$. Alzheimers Dement 13, 1004-1012 (2017).

82. P. K. Crane, et al., Development and assessment of a composite score for memory in the Alzheimer's Disease Neuroimaging Initiative (ADNI). Brain Imaging and Behavior 6, 502-516 (2012).

83. L. E. Gibbons, et al., A composite score for executive functioning, validated in Alzheimer's Disease Neuroimaging Initiative (ADNI) participants with baseline mild cognitive impairment. Brain Imaging and Behavior 6, 517-527 (2012).

84. K. J. Gorgolewski, et al., The brain imaging data structure, a format for organizing and describing outputs of neuroimaging experiments. Scientific Data 3, 1-9 (2016).

85. O. Esteban, et al., MRIQC: Advancing the automatic prediction of image quality in MRI from unseen sites. PLOS ONE 12, e0184661 (2017). 
medRxiv preprint doi: https://doi.org/10.1101/2021.01.13.21249597; this version posted January 21, 2021. The copyright holder for this preprint (which was not certified by peer review) is the author/funder, who has granted medRxiv a license to display the preprint in perpetuity.

All rights reserved. No reuse allowed without permission.

86. O. Esteban, et al., fMRIPrep: a robust preprocessing pipeline for functional MRI. Nat. Methods 16, 111116 (2019).

87. N. J. Tustison, et al., N4ITK: Improved N3 Bias Correction. IEEE Transactions on Medical Imaging 29, 1310-1320 (2010).

88. A. M. Dale, B. Fischl, M. I. Sereno, Cortical Surface-Based Analysis: I. Segmentation and Surface Reconstruction. Neurolmage 9, 179-194 (1999).

89. B. B. Avants, C. L. Epstein, M. Grossman, J. C. Gee, Symmetric diffeomorphic image registration with cross-correlation: Evaluating automated labeling of elderly and neurodegenerative brain. Medical Image Analysis 12, 26-41 (2008).

90. R. W. Cox, AFNI: software for analysis and visualization of functional magnetic resonance neuroimages. Computers and Biomedical research 29, 162-173 (1996).

91. M. Jenkinson, P. Bannister, M. Brady, S. Smith, Improved optimization for the robust and accurate linear registration and motion correction of brain images. Neuroimage 17, 825-841 (2002).

92. D. N. Greve, B. Fischl, Accurate and robust brain image alignment using boundary-based registration. Neurolmage 48, 63-72 (2009).

93. Y. Behzadi, K. Restom, J. Liau, T. T. Liu, A component based noise correction method (CompCor) for BOLD and perfusion based fMRI. Neurolmage 37, 90-101 (2007).

94. J. D. Power, et al., Methods to detect, characterize, and remove motion artifact in resting state fMRI. Neurolmage 84, 320-341 (2014).

95. A. Abraham, et al., Machine learning for neuroimaging with scikit-learn. Front. Neuroinform. 8 (2014).

96. K. J. Friston, A. Holmes, J. B. Poline, C. J. Price, C. D. Frith, Detecting activations in PET and fMRI: Levels of inference and power. Neurolmage 4, 223-235 (1996).

97. L. Lemieux, A. Salek-Haddadi, T. E. Lund, H. Laufs, D. Carmichael, Modelling large motion events in fMRI studies of patients with epilepsy. Magnetic Resonance Imaging 25, 894-901 (2007).

98. T. Alakörkkö, H. Saarimäki, E. Glerean, J. Saramäki, O. Korhonen, Effects of spatial smoothing on functional brain networks. Eur J Neurosci 46, 2471-2480 (2017).

99. X. Shen, F. Tokoglu, X. Papademetris, R. T. Constable, Groupwise whole-brain parcellation from restingstate fMRI data for network node identification. Neuroimage 82, 403-415 (2013).

100. E. S. Finn, et al., Functional connectome fingerprinting: Identifying individuals based on patterns of brain connectivity. Nat Neurosci 18, 1664-1671 (2015).

101. S. Noble, et al., Influences on the Test-Retest Reliability of Functional Connectivity MRI and its Relationship with Behavioral Utility. Cereb Cortex 27, 5415-5429 (2017).

102. M. Xia, J. Wang, Y. He, BrainNet Viewer: A Network Visualization Tool for Human Brain Connectomics. PLOS ONE 8, e68910 (2013).

103. A. Fornito, A. Zalesky, E. T. Bullmore, Network scaling effects in graph analytic studies of human restingstate fMRI data. Front. Syst. Neurosci. 4 (2010).

104. A. Zalesky, et al., Whole-brain anatomical networks: Does the choice of nodes matter? Neurolmage 50, 970-983 (2010).

105. M. F. Glasser, et al., A multi-modal parcellation of human cerebral cortex. Nature 536, 171-178 (2016). 
medRxiv preprint doi: https://doi.org/10.1101/2021.01.13.21249597; this version posted January 21, 2021. The copyright holder for this preprint (which was not certified by peer review) is the author/funder, who has granted medRxiv a license to display the preprint in perpetuity.

All rights reserved. No reuse allowed without permission.

\section{Figures and Tables}

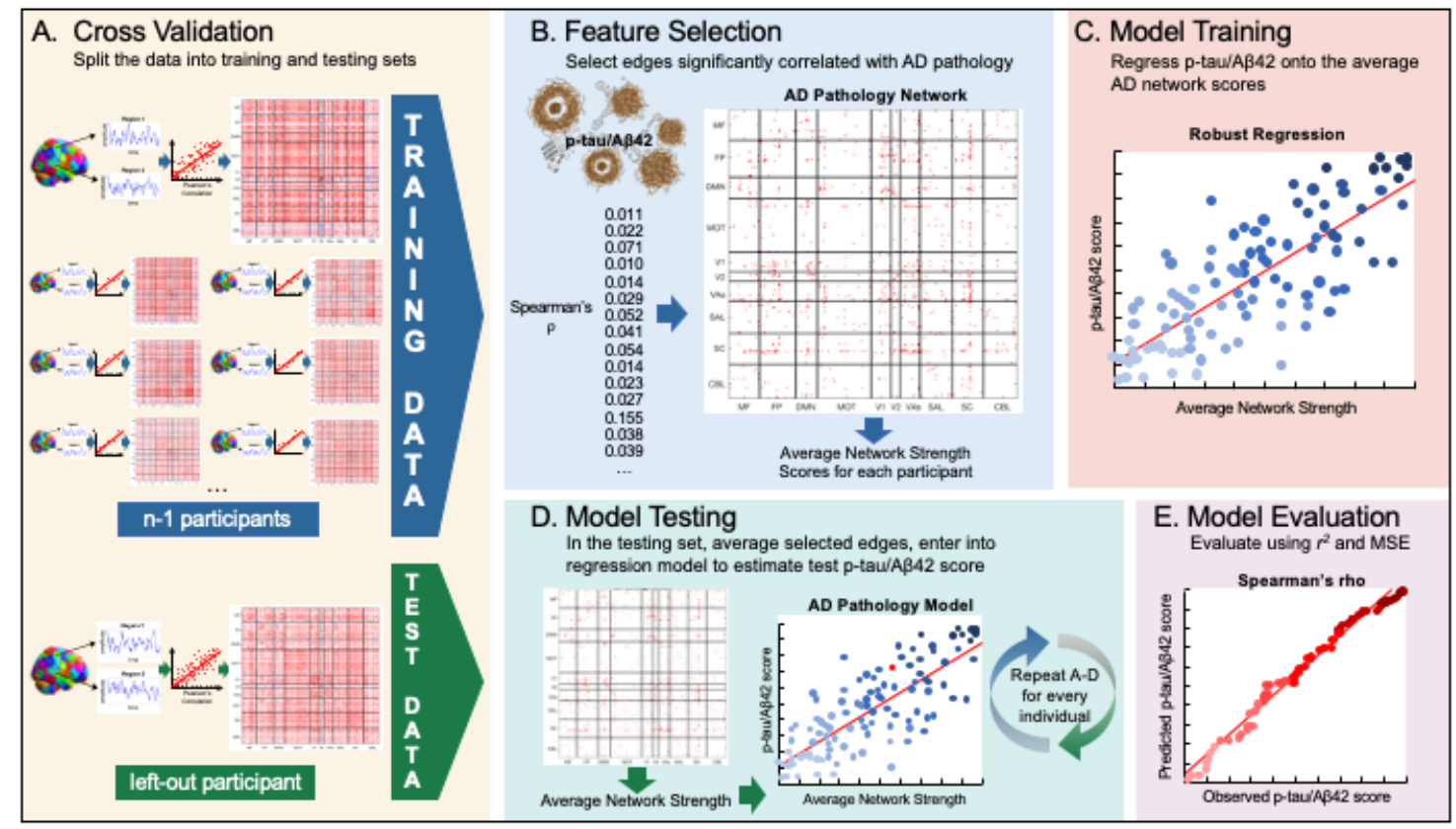

Figure 1. Schematic Presentation of CPM Model. 


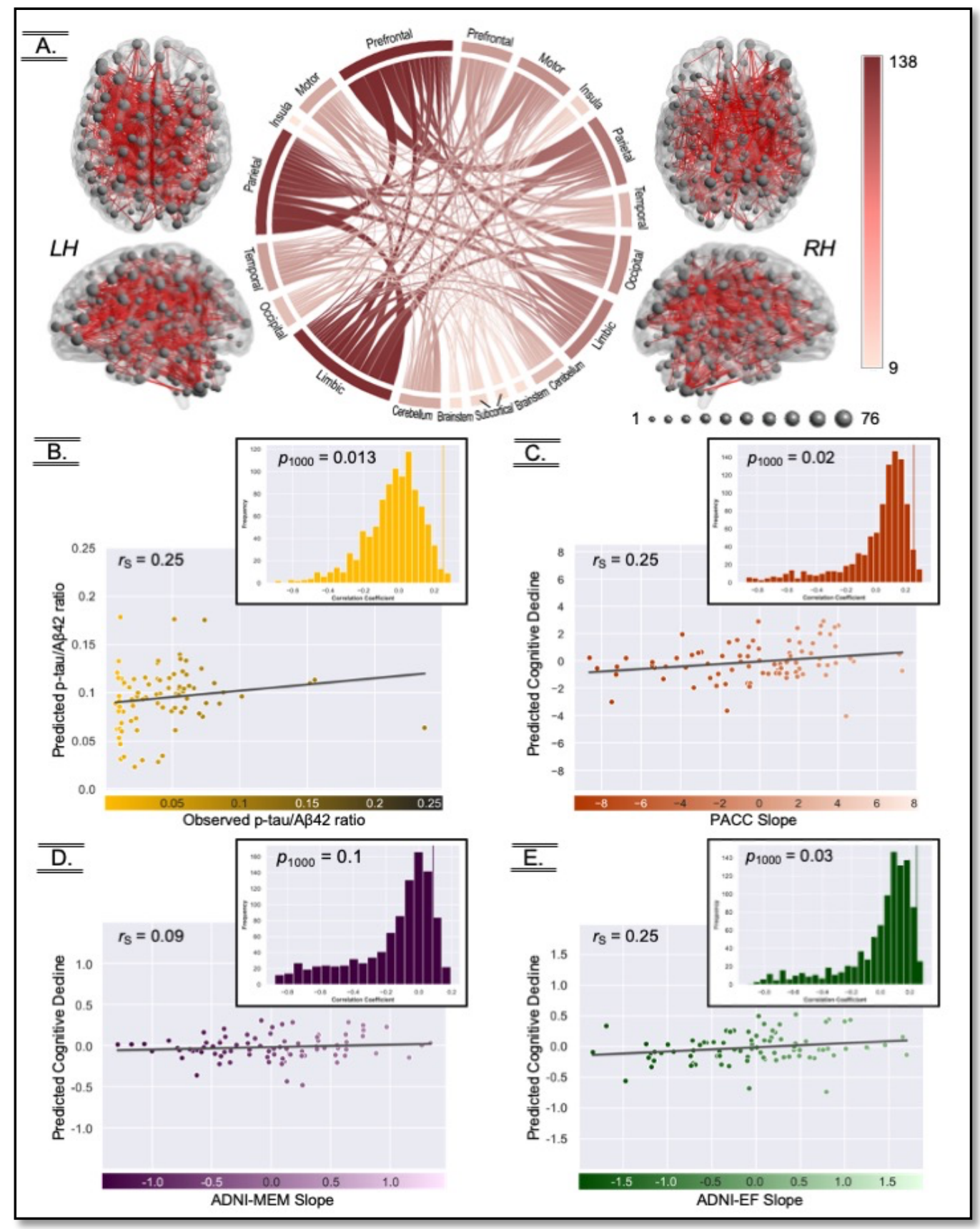

Figure 2. Visual depiction of the PATH-fc model and the in-sample fit for AD pathology and cognitive decline. A. Presents the anatomical distribution of the PATH-fc model. The 581 edges included nodes in all the macroscale regions, with the left hemisphere showing greater involvement than the right. B. Internal model fit of the PATH-fc model to the ADNI pathology data. C-E. Internal model fit of the PATH-fc model to predict cognitive decline in PACC, ADNI-MEM, and ADNI-EF, respectively. The scatterplots represent Spearman correlation between observed scores (AD pathology, PACC, ADNI-MEM, and ADNI-EF) and predicted scores for the same metric derived using cross-validation. Histogram represents the randomly shuffled connectivity matrices and respective metric pairings over 1000 iterations to compute the final $p$-value for the significance. 


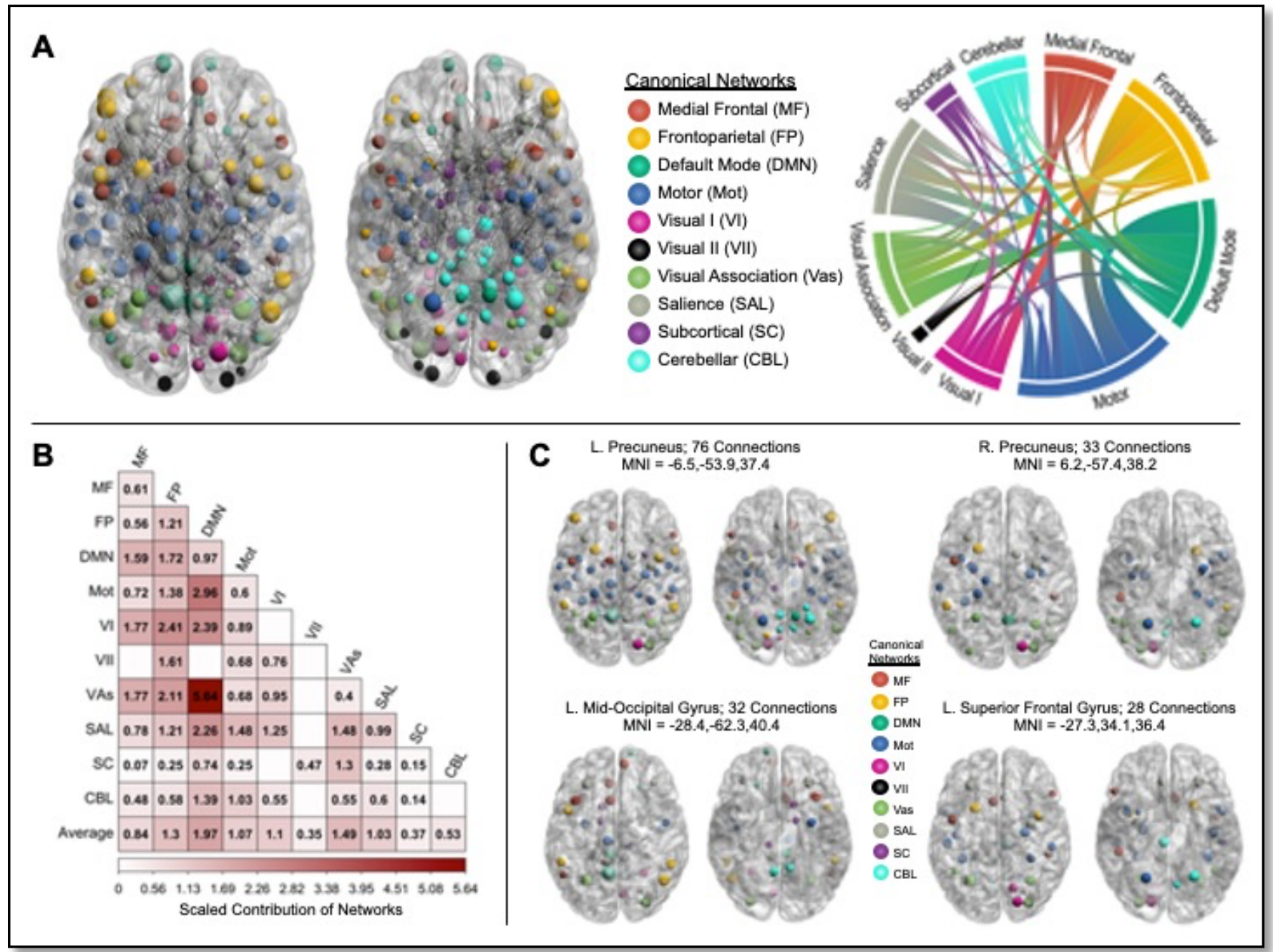

Figure 3. Network localization of the PATH-fc model. A. Presents the involvement of the 10 canonical networks in the PATH-fc model, with nodes parcellated based on Noble et al. (2019).Ribbons in the ring plot visualization are proportional to the representation of each network in the PATH-fc model. The matrix presented in panel B shows the relative contribution of each network to the PATH-fc model adjusted using the formula described in Greene et al., 2019. Panel $\mathrm{C}$ highlights the anatomical and network localization of the four high degree nodes in the PATH-fC model, with two nodes belonging to the default mode network, one to the salience network, and one the visual association network. 
medRxiv preprint doi: https://doi.org/10.1101/2021.01.13.21249597; this version posted January 21, 2021. The copyright holder for this preprint (which was not certified by peer review) is the author/funder, who has granted medRxiv a license to display the preprint in perpetuity.

All rights reserved. No reuse allowed without permission.

Table 1. Baseline characteristics of participants by diagnostic groups.

$\operatorname{MCl}(n=62)$

$A D(n=21)$

Characteristic

Mean (SD) or N (\%)

Range

Mean (SD) or N (\%)

Range

Sex

$\begin{array}{lllll}\text { Female } & 25 & (40.3 \%) & 10 & (47.6 \%) \\ \text { Male } & 37 & (59.7 \%) & 11 & (52.4 \%)\end{array}$

Race* $^{*}$

$\begin{array}{lcccc}\text { White } & 57 & (91.9 \%) & 19 & (90.5 \%) \\ \text { Asian } & 2 & (3.2 \%) & 2 & (9.5 \%) \\ \text { Black } & 1 & (1.6 \%) & 0 & (0 \%) \\ \begin{array}{l}\text { More than One } \\ \text { Race }\end{array} & 1 & (1.6 \%) & 0 & (0 \%) \\ \text { Unknown } & 1 & (1.6 \%) & 0 & (0 \%)\end{array}$

Age (years)

Years of education

$A P O E$

$\varepsilon 4$ allele absent

32

21

9

$2 \_4$ alleles

P-tau/A $\beta_{42}$

1 \&4 allele

0.0374

(0.0364)

0.0078 to

0.2357

0.0604

3

13

5

(61.9\%)

(14.5\%)

55.5 to 88.6

73.3

15.8

(2.7)

(14.3\%)

(23.8\%)

55.9 to 86.5

12 to 20

\begin{tabular}{|c|c|c|c|c|c|c|}
\hline Baseline PACC & -4.7 & $(3.3)$ & -12.6 to 0.7 & -15.4 & $(3.4)$ & -9 \\
\hline Baseline ADNI-MEM & 0.3 & $(0.6)$ & -0.9 to 1.7 & -1.0 & $(0.7)$ & -2.7 \\
\hline Baseline ADNI-EF & 0.5 & $(0.9)$ & -1.7 to 2.4 & -1.0 & $(0.8)$ & -2.2 \\
\hline
\end{tabular}


medRxiv preprint doi: https://doi.org/10.1101/2021.01.13.21249597; this version posted January 21, 2021. The copyright holder for this preprint

(which was not certified by peer review) is the author/funder, who has granted medRxiv a license to display the preprint in perpetuity.

All rights reserved. No reuse allowed without permission.

Table 2. Estimated slopes (change in outcome for 1 month increase in time) over two years for cognitive outcomes from linear mixed effects models

\begin{tabular}{|c|c|c|c|c|c|c|c|c|c|}
\hline \multirow[b]{2}{*}{ Measure } & \multicolumn{3}{|c|}{ Overall $(n=83)$} & \multicolumn{3}{|c|}{$M C I(n=62)$} & \multicolumn{3}{|c|}{$A D(n=21)$} \\
\hline & Slope & (SE) & $p$-value & Slope & (SE) & p-value & Slope & (SE) & $p$-value \\
\hline PACC & -0.12 & $(0.021)$ & $<.0001$ & -0.07 & $(0.022)$ & 0.004 & -0.29 & $(0.050)$ & $<.0001$ \\
\hline ADNI-MEM & -0.0086 & $(0.0024)$ & 0.0006 & -0.007 & $(0.0025)$ & 0.009 & -0.014 & $(0.0059)$ & 0.02 \\
\hline ADNI-EF & -0.015 & $(0.0036)$ & $<.0001$ & -0.006 & $(0.0039)$ & 0.11 & -0.042 & $(0.0087)$ & $<.0001$ \\
\hline
\end{tabular}


medRxiv preprint doi: https://doi.org/10.1101/2021.01.13.21249597; this version posted January 21, 2021. The copyright holder for this preprint (which was not certified by peer review) is the author/funder, who has granted medRxiv a license to display the preprint in perpetuity.

All rights reserved. No reuse allowed without permission.

Supplementary Tables and Figures

Table S1. Internal Validation Prediction Results at Various Edge Selection Thresholds. High pathology model performance was comparable across various edge-selection thresholds.

\begin{tabular}{|c|c|c|c|}
\hline $\begin{array}{l}\text { Edge-selection p- } \\
\text { value threshold }\end{array}$ & $\begin{array}{l}\text { Spearman's } \\
\text { correlation }\end{array}$ & p-value & $\begin{array}{l}\text { Number of } \\
\text { predictive edges }\end{array}$ \\
\hline 0.1 & 0.19 & 0.020 & 4669 \\
\hline 0.05 & 0.20 & 0.023 & 2533 \\
\hline 0.005 & 0.28 & 0.013 & 305 \\
\hline 0.001 & 0.32 & 0.016 & 63 \\
\hline
\end{tabular}

Note: $p$-values were obtained after 1000 iteration permutation testing (described in Derivation of PATHfc functional connectivity model). 
medRxiv preprint doi: https://doi.org/10.1101/2021.01.13.21249597; this version posted January 21, 2021. The copyright holder for this preprint (which was not certified by peer review) is the author/funder, who has granted medRxiv a license to display the preprint in perpetuity.

All rights reserved. No reuse allowed without permission.

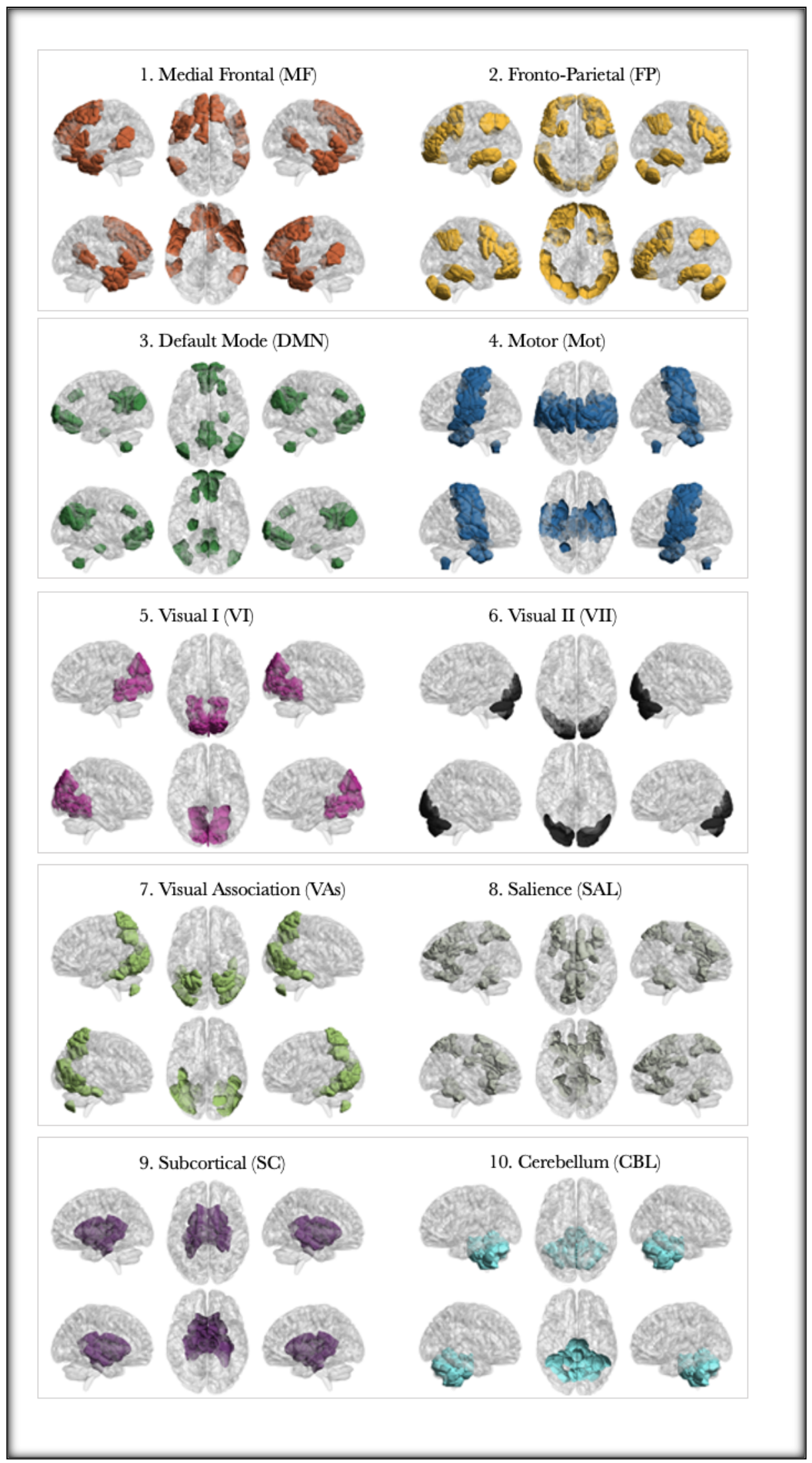

Figure S1: Presents the 10 canonical networks used for network localization of the PATH-fc model. 

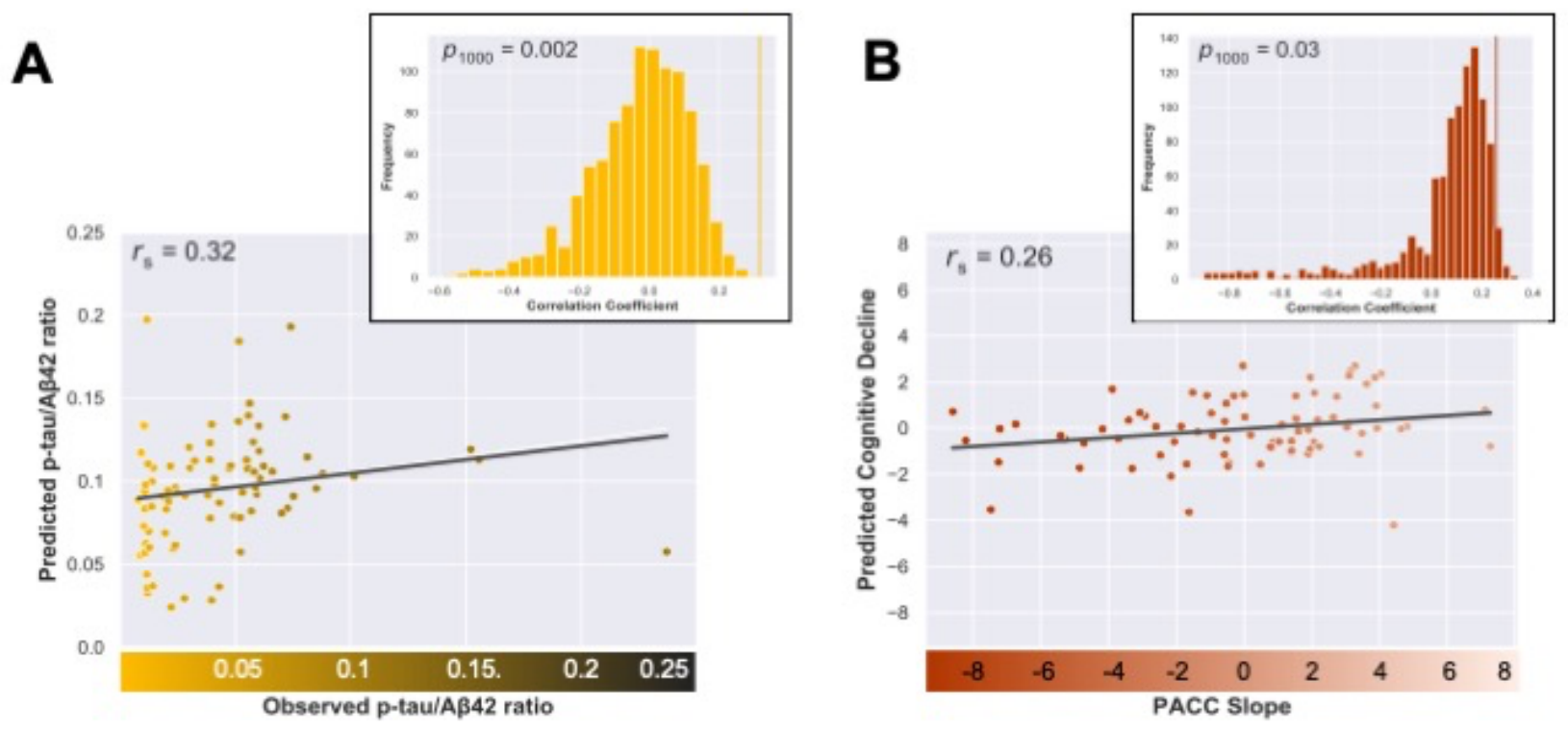

C
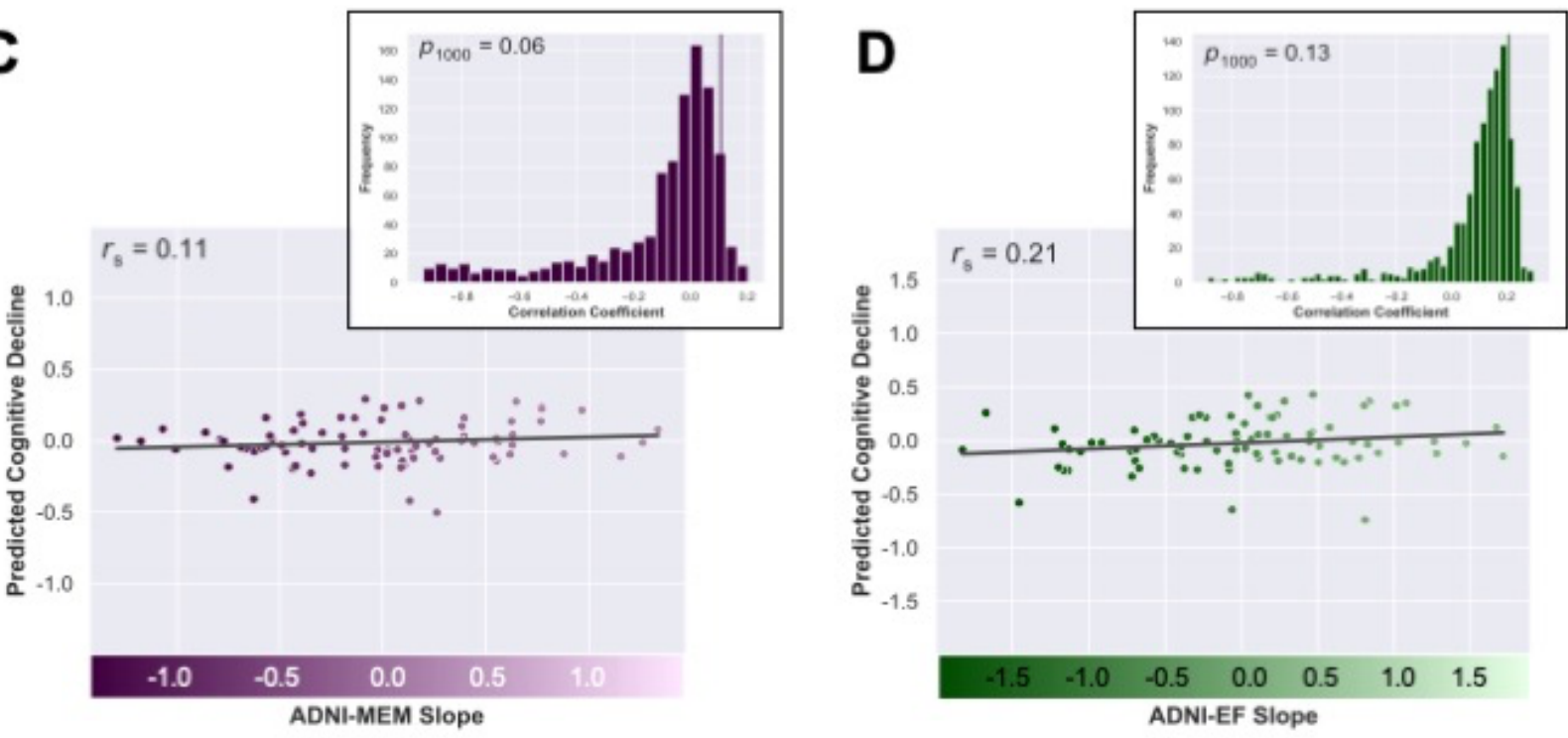

Figure S2: Results of the internal model fit of the PATH-fc model generated using the Glasser atlas. Internal model fit is shown for p-tau/AB42 ratio (A), and declines in PACC scores (B), ADNI-MEM (C), and ADNI-EF (D). The scatterplots represent Spearman correlation between observed scores (AD pathology, PACC, ADNI-MEM, and ADNI-EF) and predicted scores for the same metric derived using cross-validation. Histogram represents the randomly shuffled connectivity matrices and respective metric pairings over 1000 iterations to compute the final $p$-value for the significance. 
medRxiv preprint doi: https://doi.org/10.1101/2021.01.13.21249597; this version posted January 21, 2021. The copyright holder for this preprint (which was not certified by peer review) is the author/funder, who has granted medRxiv a license to display the preprint in perpetuity.

A
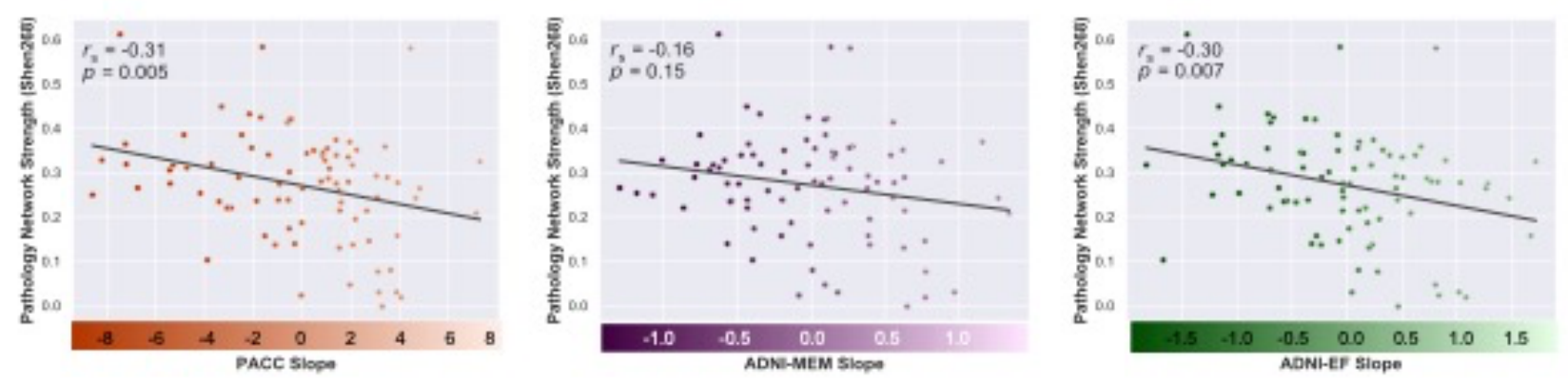

B
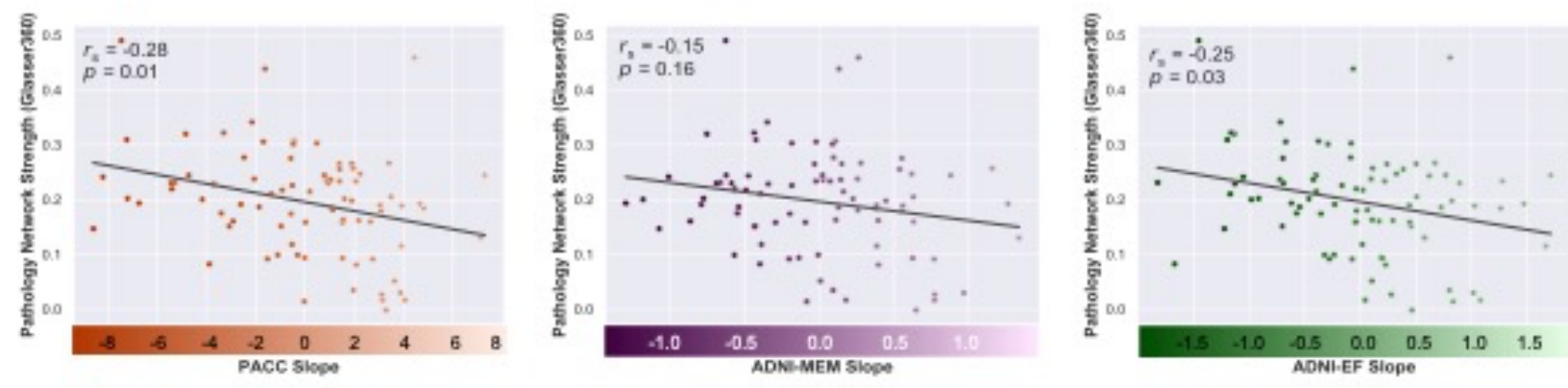

Figure S3: Panel A shows the correlation between network strength of the PATH-fc model and decline in composite scores for the three domains of cognition. The PATH-fc model was derived using the parcellation scheme of the Shen atlas. To ensure that our model was robust to the choice of atlas, we also replicated the analyses using the Glasser atlas. Panel B presents the results from the Glasser atlas derivation, with the scatter plots showing a correlation between network strength of the PATH-fc model and decline in cognitive functioning. 